\title{
Catecholato complexes of cobalt and nickel with 1,4-disubstituted-1,4-diazabutadiens-1,3 and 1,2-bis(diphenylphosphino)ethane
}

\author{
MICHAEL P BUBNOV ${ }^{\mathrm{a}, \mathrm{b}, *}$, IRINA A TEPLOVA ${ }^{\mathrm{a}}$, NIKOLAY O DRUZHKOV ${ }^{\mathrm{a}}$, \\ GEORGY K FUKIN ${ }^{\mathrm{a}, \mathrm{b}}$, ANNA V CHERKASOVA ${ }^{\mathrm{a}}$ and VLADIMIR K CHERKASOV ${ }^{\mathrm{a}, \mathrm{b}}$ \\ ${ }^{\mathrm{a}} \mathrm{G}$ A Razuvaev Institute of Organometallic Chemistry of RAS, 603950 Tropinina str. 49, GSP-445, \\ Nizhny Novgorod, Russia \\ b Lobachevsky State University of Nizhny Novgorod, 23 Prospekt Gagarina, 603950, Nizhny Novgorod, Russia \\ e-mail: bmp@iomc.ras.ru
}

MS received 03 June 2014; revised 19 September 2014; accepted 24 September 2014

\begin{abstract}
Divalent cobalt and nickel form four-coordinate complexes with sterically hindered 3,6-di-tertbutylcatecholato dianion (3,6-DBCat) and neutral bidentate 1,4-disubstituted-1,4-diazabutadiens-1,3 (DAB). Structural study of (1,4-di-tert-butyl-1,4-diazabutadiene-1,3)(3,6-di-tert-butyl-catecolato)nickel and (1,4-bis(2,6-di-iso-propylphenyl)-2,3-dimethyl-1,4-diazabutadiene-1,3)(3,6-di-tert-butyl-catecolato)cobalt indicates square-planar environment of metals. Chemical one-electron oxidation of nickel complexes proceeds through catecholate ligand and leads to $o$-semiquinonato adducts. EPR spectral parameters indicate preservation of square-planar configuration after oxidation. Complexes (DAB) $\mathrm{M}(\mathrm{Cat})(\mathrm{M}=\mathrm{Ni}, \mathrm{Co})$ undergo neutral ligand substitution reactions.
\end{abstract}

Keywords. Catecholates; diazabutadienes; cobalt; nickel; ligand exchange; oxidation; structural study.

\section{Introduction}

A feature of catecholato ligands is their ability to undergo easy one-electron oxidation forming semiquinones. ${ }^{1,2}$ Reversible one-electron oxidation accompanied by structural transformation occurring in a complex molecule leads to equilibrium of two isomers differing by charge distribution between metal and ligand. This phenomenon is called valent tautomerism or redox-isomerism. ${ }^{3-6}$ In the case of copper, the redox-isomeric transformation was observed on complexes containing 1,4-disubstituted-1,4-diazabutadiens1,3 as neutral ancillary ligand and catecholate as redox active ligand (scheme 1). Basing on the general consideration of the theory of ligand field splitting, the authors ${ }^{4}$ have proposed that reversible electron transfer is accompanied by structural transformation. Squareplanar geometry was attributed to catecholato derivative of copper (II) whereas the distorted tetrahedral was attached to semiquinonato complex of copper (I). Sterical hindrances of both DAB and SQ-ligands

*For correspondence and semiquinonate acceptor properties influence the equilibrium position.

Cobalt and nickel are the predecessors before copper in the first row of transition metals. The aim of this work is synthesis of similar complexes of cobalt and nickel and searching for new complexes demonstrating reversible intramolecular electron transfer in solution.

We have found two structurally characterized diazabutadiene nickel catecholates: (1,4-bis-(2,6-di-isopropylphenyl)-2,3-dimethyl-1,4-diazabutadiene-1,3)(3, 4,5,6- $\mathrm{Cl}_{4}$-catecolato)nickel and (1,4-bis-(2,6-di-methylphenyl)-2,3-dimethyl-1,4-diazabutadiene-1,3)(3,4,5, 6- $\mathrm{Cl}_{4}$-catecolato)nickel which were used as precursors for olefin polymerization catalysts. ${ }^{7}$ Reversible interconversion of redox isomers was observed in complex (N,N'-bis(3,5-di-tert-butyl-salicylidene)-1,2cyclohexanediamino)nickel cation. ${ }^{8}$ It is the equilibrium between $\mathrm{Ni}(\mathrm{III})$-phenolato form of complex (at low temperature) and $\mathrm{Ni}(\mathrm{II})$-phenoxyl radical one (at ambient temperature). Several examples of monocatecholato complexes of cobalt and nickel with phosphins $\left(\mathrm{PMe}_{3}\right.$, dppe $)$ have been already described. ${ }^{9,10}$ There are also some examples of chemical control of electronic state of nickel complexes with catecholate ligand. ${ }^{11,12}$ 


\section{$(\mathrm{DAB}) \mathrm{Cu}^{\prime \prime}(\mathrm{Cat}) \stackrel{\Delta}{\rightleftharpoons}(\mathrm{DAB}) \mathrm{Cu}^{\prime}(\mathrm{SQ})$}

Scheme 1. Copper valent tautomers interconversion (DAB = 1,4-diazabutadiene-1,3; SQ and Cat = anion-radical and dianion of substituted o-quinone respectively).

\section{Experimental}

\subsection{General considerations}

Cobalt(II) chloride, nickel tetracarbonyl, amines, dppe, diacetil, glyoxal water solution $(40 \%)$, were received from commercial sources (Aldrich, Fluka). 3,6-Di-tert-butyl- $o$-quinone-1,2 was obtained according to known procedures. ${ }^{13}$ Solvents were carefully dried and in most cases were degassed before using. Diazabutadiens were obtained according to known procedures. ${ }^{14}$ EPR spectra were recorded on "Bruker ER-200 SRC", IR - on "Specord M-80". X-ray structural studies were performed on "Smart Apex" (Bruker AXS). The most synthetic procedures were carried out in evacuated ampoules.

\subsection{Synthesis and characterization of diazabutadiene- catecholato nickel complexes}

General procedure: Nickel tetracarbonyl (1 mmol) was condensed into evacuated frozen ampoule (of approximately $200 \mathrm{~mL}$ volume) containing $1 \mathrm{mmol}$ of 3,6-ditert-butyl-o-quinone $+1 \mathrm{mmol}$ corresponding diazabutadiene in $50 \mathrm{~mL}$ of degassed toluene. Ampoule was slowly warmed at $\sim 30^{\circ} \mathrm{C}$ for half an hour and at $\sim 80^{\circ} \mathrm{C}$ during the next two hours. It was necessary to freeze and evacuate ampoule periodically every ten minutes for removing $\mathrm{CO}$. Resulting solution was allowed to stay for a night at $-10^{\circ} \mathrm{C}$. Crystalline solid was filtered, washed with light petroleum and dried under vacuum. Yields and properties are listed below.

\section{2a (1,4-di-tert-butyl-1,4-diaza-1,3-butadiene)(3,6-} di-tert-butyl-catecholato)nickel(1): Green solid. Slowly decomposes in air. Yield 45\%. Anal. (\%) Found: C 64.80; H 9.02; Ni 13.07. $\mathrm{C}_{24} \mathrm{H}_{40} \mathrm{~N}_{2} \mathrm{O}_{2} \mathrm{Ni}$ Calc.: C 64.43; H 8.95; Ni 13.20. IR (Nujol), $v, \mathrm{~cm}^{-1}: 1600 \mathrm{w}, 1555$, $1540,1540,1410 \mathrm{~s}, 1400 \mathrm{~s}, 1370 \mathrm{~s}, 1325 \mathrm{w}, 1280 \mathrm{w}$, $1265 \mathrm{~s}, 1250 \mathrm{~s}, 1210 \mathrm{~s}, 1150 \mathrm{w}, 1100 \mathrm{w}, 1030 \mathrm{w}, 985 \mathrm{~s}$, $960 \mathrm{w}, 945 \mathrm{~m}, 875 \mathrm{~m}, 830 \mathrm{w}, 795,785 \mathrm{~m}, 700 \mathrm{~s}, 655 \mathrm{~m}$, $615 \mathrm{~m}, 545 \mathrm{w}, 520 \mathrm{w}$.

2.2b (1,4-bis-(2,6-di-iso-propylphenyl)-1,4-diaza-1,3butadiene)(3,6-di-tert-butyl-catecholato)nickel (2): Dark green airstable crystals. Yield 65\%. Anal.(\%) Found: C
72.94; $\mathrm{H}$ 8.79; Ni 8.95. $\mathrm{C}_{40} \mathrm{H}_{56} \mathrm{~N}_{2} \mathrm{O}_{2} \mathrm{Ni}$ Calc.: C 73.28; H 8.55; Ni 9.01. IR (Nujol, $\mathrm{cm}^{-1}$ ): $1590 \mathrm{w}, 1550 \mathrm{w}$, $1370 \mathrm{~m}, 1360 \mathrm{~m}, 1320 \mathrm{~s}, 1305 \mathrm{~s}, 1275 \mathrm{~s}, 1260 \mathrm{~s}, 1210 \mathrm{~s}$, $1180 \mathrm{~s}, 1040 \mathrm{~s}, 985 \mathrm{~s}, 940 \mathrm{~m}, 870 \mathrm{~m}, 860 \mathrm{~m}, 785 \mathrm{~s}$, 750 s, 700 s, 655 s, 620 m, 595 m, 515 m, 490 w.

2.2c (2,3-dimethyl-1,4-bis-(2,6-di-iso-propylphenyl)1,4-diaza-1,3-butadiene)(3,6-di-tert-butyl-catecholato) nickel (3): Dark green airstable crystals. Yield $80 \%$. Anal.(\%) Found: C 73.48; $\mathrm{H}$ 8.70; Ni 8.85. $\mathrm{C}_{42} \mathrm{H}_{60} \mathrm{~N}_{2} \mathrm{O}_{2} \mathrm{Ni}$ Calc.: C 73.79; $\mathrm{H}$ 8.78; Ni 8.64. IR (Nujol, $\mathrm{cm}^{-1}$ ): $1595 \mathrm{w}, 1580 \mathrm{w}, 1505 \mathrm{~s}, 1405 \mathrm{~s}, 1370 \mathrm{~m}$, $1345 \mathrm{~s}, 1320 \mathrm{~s}, 1305 \mathrm{~s}, 1275 \mathrm{~s}, 1215 \mathrm{~s}, 1065$ w, 985 s, $950 \mathrm{~m}, 890 \mathrm{w}, 880 \mathrm{w}, 835 \mathrm{w}, 785 \mathrm{~m}, 740 \mathrm{~m}, 715 \mathrm{w}, 705 \mathrm{w}$, $655 \mathrm{w}, 620 \mathrm{~m}, 515 \mathrm{w}$.

2.2d (1,4-bis-(2,6-dimethylphenyl)-1,4-diaza-1,3-butadiene)(3,6-di-tert-butyl-catecholato)nickel(4): Dark green air stable solid. Yield 55\%. Anal.(\%) Found: C 70.50; $\mathrm{H}$ 7.71; Ni 10.56. $\mathrm{C}_{32} \mathrm{H}_{40} \mathrm{~N}_{2} \mathrm{O}_{2} \mathrm{Ni}$ Calc.: C 70.73; $\mathrm{H}$ 7.42; Ni 10.80. IR (Nujol), v, $\mathrm{cm}^{-1}: 1720,1600,1555$, 1460, 1360, $1320 \mathrm{~s}, 1305 \mathrm{~s}, 1245,1205 \mathrm{~s}$.

2.2e (2,2'-dipyridine)(3,6-di-tert-butyl-catecholato)nickel (5) from $\mathrm{Ni}(\mathrm{CO})_{4}$ : Blue-grey air sensitive solid. Yield 42\%. Anal.(\%) Found: C 65.87; H 6.45; Ni 13.96. $\mathrm{C}_{24} \mathrm{H}_{28} \mathrm{~N}_{2} \mathrm{O}_{2} \mathrm{Ni}$ Calc.: $\mathrm{C}$ 66.24; $\mathrm{H}$ 6.49; Ni 13.49. IR (Nujol, $\mathrm{cm}^{-1}$ ): $1615 \mathrm{w}, 1605 \mathrm{~m}, 1420 \mathrm{~s}, 1290 \mathrm{~m}, 1280 \mathrm{~m}$, 1255 m, 990m, 950 m, 785 s, 770 s, 730 m, 655 w, $625 \mathrm{w}$.

2.2f (2,2'-dipyridine)(3,6-di-tert-butyl-catecholato) nickel (5) from (DME) $\mathrm{NiCl}_{2}$ :(DME) $\mathrm{NiCl}_{2}$ was obtained by treatment of nickel powder by bromine in DME. Dithallium 3,6-di-tert-butyl-catecholate (prepared from 3,6-di-tert-butyl-o-benzoquinone $(0.11 \mathrm{~g}, 0.5 \mathrm{mmol})$ as it is described below) was added to the suspension containing (DME) $\mathrm{NiCl}_{2}(0.11 \mathrm{~g}, 0.5 \mathrm{mmol})$ and $2,2^{\prime}-$ bipyridine $(0.078 \mathrm{~g}, 0.5 \mathrm{mmol})$ in THF $(50 \mathrm{~mL})$. The mixture was warmed $\left(\sim 80^{\circ} \mathrm{C}\right)$ and shaken during one hour, filtered and concentrated. After the $n$-hexane addition, dark microcrystalline solid was formed. It was filtered, washed with light petroleum and dried under vacuum. Yield $30 \%$.

$2.2 \mathrm{~g}$ (1,2-bis(diphenylphosphino)ethane)(3,6-di-tertbutyl-catecholato)nickel $*$ toluene (6): [1,2]-bis(diphenylphosphino)ethane nickel(II) chloride was obtained analogously to known procedure. ${ }^{15}$ The mixture of commercial $\mathrm{NiCl}_{2} \cdot 2 \mathrm{H}_{2} \mathrm{O}(13.2 \mathrm{~g}, 0.08 \mathrm{~mol})$ in $40 \mathrm{~mL}$ 
$\mathrm{H}_{2} \mathrm{O}$ with acetic acid $(140 \mathrm{~mL})$ was added to warm solution of 1,2-bis(diphenylphosphino)ethane (31.8 g, $0.08 \mathrm{~mol})$ in acetic acid $(570 \mathrm{~mL})$ with stirring. Reaction mixture was allowed to stay for ten hours. Pinkbrown crystals were filtered, washed with cold acetic acid and dried in vacuum. Yield: $40.1 \mathrm{~g}(95 \%)$.

Suspension of di-thallium-3,6-di-tert-butyl-catecholate prepared from $o$-quinone $(0.044 \mathrm{~g}, 0.2 \mathrm{mmol})$ as it is described below in THF $(10 \mathrm{~mL})$, was added to [1,2-bis(diphenylphosphino)ethane]nickel(II) chloride $(0.1 \mathrm{~g}, 0.2 \mathrm{mmol})$ in THF $(40 \mathrm{~mL})$ in evacuated ampoule. Reaction mixture was refluxed for one hour. Solvent was changed to the mixture toluene/ $\mathrm{CH}_{2} \mathrm{Cl}_{2}$ $(\sim 10 / 1,50 \mathrm{~mL})$, the mixture was filtered; solution volume was reduced to one half. Dark green solid, formed after cooling, was filtered, washed with light petroleum and dried in vacuum. Yield: $0.068 \mathrm{~g}(53 \%)$. According to element analysis it contains toluene molecule as solvate. Anal.(\%) Found: C 73.72; H 6.44; Ni 7.62; P 8.04. $\mathrm{C}_{47} \mathrm{H}_{52} \mathrm{P}_{2} \mathrm{O}_{2} \mathrm{Ni}$ Calc.: C 73.37; H 6.76; Ni 7.64; P 8.07. IR (Nujol), v, $\mathrm{cm}^{-1}: 1595,1485,1440 \mathrm{~s}, 1410,1275$, $1255,1190,1110 \mathrm{~s}, 1035,980,940,880,830,795,745$, $725 \mathrm{~s}, 710 \mathrm{~s}, 690 \mathrm{~s}, 660,540,480,450$.

\subsection{Synthesis and characterization of diazabutadiene- catecholato cobalt complexes}

2.3a General procedure: Evacuated ampoule containing $1 \mathrm{mmol}$ of 3,6-di-tert-butyl-o-quinone in THF and excess of thallium amalgam (at least 10-fold excess of Tl) was shaken until the suspension colour became bright yellow. The light suspension of di-thallium catecholate was carefully decanted to another evacuated ampoule. Thallium amalgam was carefully washed several times by THF until the solution became colourless. (Attention! Di-thallium catecholate is extremely air sensitive.) United solutions of di-thallium catecholate were added to the mixture of corresponding diazabutadiene ( $\alpha, \alpha^{\prime}$-bpy, dppe) ( $1 \mathrm{mmol}$ ) and dry $\mathrm{CoCl}_{2}(1 \mathrm{mmol})$ in THF. Reaction mixture was refluxed during one hour. Solvent was changed to toluene (or light petroleum). Solution was filtered, partly evaporated and allowed to stay at $-10^{\circ} \mathrm{C}$ for a night. Resulting crystalline solid was filtered, washed by cold light petroleum and dried under vacuum. Yields and properties are listed below.

2.3b (1,4-di-tert-butyl-1,4-diaza-1,3-butadiene)(3,6di-tert-butyl-catecholato)cobalt (7): Blue-grey crystals. Slowly decomposes in air. Yield 33\%. Anal.(\%) Found: C 64.70; $\mathrm{H}$ 9.22; Co 13.27. $\mathrm{C}_{24} \mathrm{H}_{40} \mathrm{~N}_{2} \mathrm{O}_{2} \mathrm{Co}$ Calc.: C 64.41; H 9.01; Co 13.17. IR (Nujol, $\mathrm{cm}^{-1}$ ):
1580 w, 1400 s, 1300 s, 1290 s, 1270 s, 1230 s, 1210 s, 1160 m, 1030 w, 990 s, 975 s, 960 s, 925 m, 890 m, $810 \mathrm{~m}, 790 \mathrm{~s}, 705 \mathrm{~m}, 680 \mathrm{~m}, 660 \mathrm{~s}, 560 \mathrm{w}, 540 \mathrm{w}, 505 \mathrm{w}$, $500 \mathrm{w}, 455 \mathrm{w}$.

2.3c (1,4-bis-(2,6-di-iso-propylphenyl)-1,4-diaza-1,3butadiene)(3,6-di-tert-butyl-catecholato)cobalt (8): Dark green crystals. Slowly decomposes in air. Yield 35\%. Anal.(\%) Found: C 73.16; H 8.78; Co 8.64. $\mathrm{C}_{40} \mathrm{H}_{56} \mathrm{~N}_{2} \mathrm{O}_{2}$ Co Calc.: C 73.29; H 8.55; Co 8.99. IR (Nujol, $\mathrm{cm}^{-1}$ ): 1480, $1450 \mathrm{~s}, 1375,1340 \mathrm{~s}, 1325,1290 \mathrm{~s}$, $1210,1185,1070,980,825,800,760 \mathrm{~m}, 710 \mathrm{~m}, 650$, $625 \mathrm{~m}$.

2.3d (2,3-dimethyl-1,4-bis-(2,6-di-iso-propylphenyl)1,4-diaza-1,3-butadiene)(3,6-di-tert-butyl-catecholato) cobalt (9): Dark blue crystals. Slowly decomposes in air. Yield 30\%. IR (Nujol, $\mathrm{cm}^{-1}$ ): $1500 \mathrm{w}, 1480 \mathrm{w}$, $1405 \mathrm{~m}, 1360 \mathrm{~m}, 1330 \mathrm{~m}, 1260 \mathrm{~m}, 1240 \mathrm{~m}, 1215,980 \mathrm{~s}$, $950 \mathrm{~m}, 890,840,790 \mathrm{~m}, 740 \mathrm{~m}, 720,660,625 \mathrm{~m}$.

2.3e (1,4-bis-(2,6-dimethylphenyl)-1,4-diaza-1,3-butadiene)(3,6-di-tert-butyl-catecholato)cobalt (10): Dark blue air sensitive crystals. Yield $61 \%$. Anal.(\%) Found: C 71.00; H 7.37; Co 10.97. $\mathrm{C}_{32} \mathrm{H}_{40} \mathrm{~N}_{2} \mathrm{O}_{2}$ Co Calc.: C 70.73; H 7.42; Co 10.80. IR (Nujol), v, $\mathrm{cm}^{-1}$ : 1675, $1630,1605,1555,1460,1360,1345,1325,1300,1275$, 1260, 1210, 1200.

\section{$2.3 f \quad\left(2,2^{\prime}\right.$-dipyridine)(3,6-di-tert-butyl-catecholato)} cobalt (11): Recrystallized from DME. Brown airstable crystals. Yield 35\%. Anal.(\%) Found: C 66.37; H 6.55; $\mathrm{Co}$ 13.66. $\mathrm{C}_{24} \mathrm{H}_{28} \mathrm{CoN}_{2} \mathrm{O}_{2}$ Calc.: C 66.20; $\mathrm{H}$ 6.48; Co 13.53. IR (Nujol, $\mathrm{cm}^{-1}$ ): $1605 \mathrm{~m}, 1585 \mathrm{w}$, $1575 \mathrm{w}, 1405 \mathrm{~s}, 1365 \mathrm{w}, 1285 \mathrm{~m}, 1270 \mathrm{~m}, 1260,1225 \mathrm{~m}$, $1205 \mathrm{~m}, 1160,1145,1025,975 \mathrm{~m}, 940 \mathrm{~m}, 925 \mathrm{w}, 780 \mathrm{w}$, $775 \mathrm{~m}, 765 \mathrm{~m}, 740 \mathrm{~m}, 700 \mathrm{w}, 680 \mathrm{~m}, 660 \mathrm{~m}$.

2.3g (Bis(diphenylphosphino)ethane)(3,6-di-tert-butylcatecholato)cobalt: Preparation procedure is described in. ${ }^{16}$ IR (Nujol, $\mathrm{cm}^{-1}$ ): $1595 \mathrm{w}, 1440 \mathrm{v} \mathrm{s}, 1395 \mathrm{v} \mathrm{s}$, $1285 \mathrm{w}, 1260 \mathrm{~s}, 1250 \mathrm{~s}, 1190 \mathrm{~m}, 1150 \mathrm{w}, 1105 \mathrm{~m}, 1030 \mathrm{w}$, $980 \mathrm{~m}, 940 \mathrm{w}, 880 \mathrm{~s}, 810 \mathrm{w}, 750 \mathrm{w}, 735 \mathrm{v} \mathrm{s}, 695 \mathrm{v} \mathrm{s}$, $680,650 \mathrm{~m}, 525,515 \mathrm{~m}, 495,480 \mathrm{w}$.

\subsection{Substitution reactions, general procedure}

All the reactions of substitution of diazabutadiene ligands by dppe and 2,2'-bpy were carried out in the same manner. Toluene solutions of ligand and corresponding 
Table 1. Crystallographic data and structure refinement details for $\mathbf{1}$ and $\mathbf{9}$.

\begin{tabular}{|c|c|c|}
\hline & 1 & 9 \\
\hline Chemical formula & $\mathrm{C}_{24} \mathrm{H}_{40} \mathrm{~N}_{2} \mathrm{NiO}_{2}$ & $\mathrm{C}_{45} \mathrm{H}_{67} \mathrm{CoN}_{2} \mathrm{O}_{2}$ \\
\hline Formula weight & 445.88 & 726.94 \\
\hline$T / \mathrm{K}$ & 293 & 100 \\
\hline Crystal system & Monoclinic & Monoclinic \\
\hline Space group & $\mathrm{C} 2 / \mathrm{c}$ & $\mathrm{C} 2 / \mathrm{c}$ \\
\hline $\mathrm{a} / \AA$ & $32.220(6)$ & $33.127(2)$ \\
\hline $\mathrm{b} / \AA$ & $23.844(5)$ & $12.6267(9)$ \\
\hline c/Å & $22.496(5)$ & 25.1845(17) \\
\hline$\beta /^{\circ}$ & 133.81(3) & 124.953(1) \\
\hline$V / \AA^{3}$ & $12472(4)$ & 8634(1) \\
\hline$Z$ & 20 & 8 \\
\hline$D_{c} / \mathrm{Mg} \mathrm{m}^{-3}$ & 1.189 & 1.118 \\
\hline$\mu / \mathrm{mm}^{-1}$ & 0.797 & 0.433 \\
\hline$F(000)$ & 4832 & 3152 \\
\hline$\theta$ Range for collection ${ }^{\circ}$ & $1.22-25.05$ & $1.81-26.07$ \\
\hline No. of reflns. colld. & 11098 & 35915 \\
\hline No. of indep. reflns. & 10891 & 8503 \\
\hline$R$ (int) & 0.0508 & 0.0685 \\
\hline$R[I>2 \sigma(I)]$ & 0.0359 & 0.0509 \\
\hline$w R$ (all data) & 0.1084 & 0.1377 \\
\hline GOF on $F^{2}$ & 0.940 & 1.008 \\
\hline Largest diff. peak and hole, $\mathrm{e} \AA^{-3}$ & $0.061 /-0.407$ & $0.713 /-0.444$ \\
\hline
\end{tabular}

complex were mixed in evacuated ampoule and slightly warmed $\left(\sim 60^{\circ} \mathrm{C}\right)$. Hexane was slowly added until precipitation began. Ampoule was allowed to stay during the time necessary to observe the end of precipitation. Solid powder was washed by warm hexane and dried under vacuum. Products were identified by full coincidence of their IR spectra with corresponding IR spectra of the same complexes obtained independently by the other way.

\section{$2.5 X$-ray crystallography}

Diffraction data were collected on a Siemens P3/PC and Bruker-AXS Smart Apex I diffractometers with graphite-monochromated Mo $\mathrm{K}_{\alpha}$ radiation $(\lambda=$ $0.71073 \AA$ ) for $\mathbf{1}$ and $\mathbf{9}$ complexes, respectively. All structures were solved by direct methods and refined against $F^{2}$ on all data by full-matrix least squares with SHELXTL. ${ }^{17}$ Absorption correction was applied using SADABS. ${ }^{18}$ All non-hydrogen atoms were refined

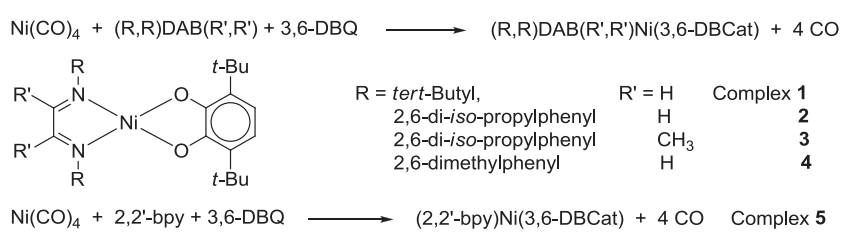

Scheme 2. Synthesis of diimine nickel catecholates. anisotropically. All hydrogen atoms in $\mathbf{1}$ and $\mathbf{9}$ were included in idealized positions and their $U_{\text {iso }}$ values were set to ride on the $U_{\text {eq }}$ values of the parent carbon atoms $\left(U_{\text {iso }}(\mathrm{H})=1.5 U_{\text {eq }}\right.$ for methyl carbons and $1.2 U_{\text {eq }}$ for other carbons). Crystallographic data and structure refinement details are given in table 1 . Asymmetric unit of $\mathbf{1}$ contains two independent molecules in common position and one molecule on $\mathrm{C}_{2}$ axes. Asymmetric unit of 9 contains one disordered hexane molecule on $\mathrm{C}_{2}$ axes.

\section{Results and Discussion}

\subsection{Synthesis and characterization of diazabutadiene- catecholato complexes of nickel and cobalt}

Nickel compounds were synthesized by one-pot reaction of nickel tetracarbonyl with corresponding diazabutadiene or 2,2'-dipyridine and $o$-quinone (scheme 2).

The exception is catecholato complex with dppe (6) which was obtained by exchange reaction of nickel(II) chloride with dppe (scheme 3 ).

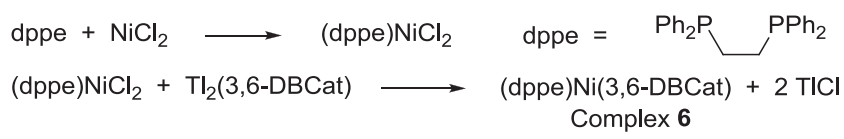

Scheme 3. Synthesis of catecholato nickel complex with 1,2-bis(diphenylphosphino)ethane. 


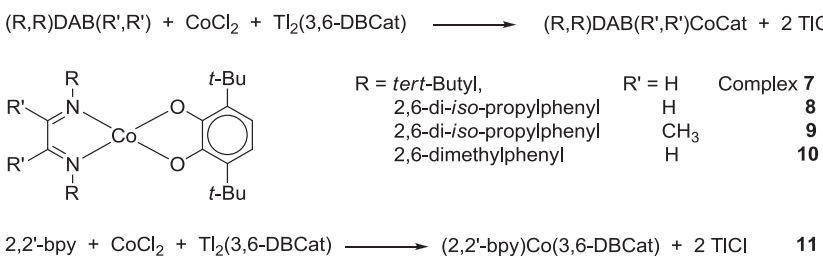

Scheme 4. Synthesis of diimine cobalt catecholates.

Catecholato complexes of cobalt were obtained by exchange reaction of cobalt(II) chloride with thallium catecholate in the presence of diazabutadiene (scheme 4).

IR spectra of all complexes are typical for catecholato metal complexes and in general represent the superposition of IR-spectra of both organic fragments: coordinated neutral DAB- ligand and catecholato dianion (see experimental section).

Complex 1 was structurally characterized. Unit cell contains three independent molecules, in which geometries are very close. Each molecule has slightly distorted square-planar geometry. Nickel atom is surrounded by two oxygen atoms of catechol and two nitrogen atoms of diazabutadiene. Each ligand's fragment itself is close to planar. The planes of the ligands are twisted by an angle varying from 5.37 to $10.93^{\circ}$. The location of the axis of twist is distinct in each molecule. In one of the molecules it coincides with the molecular twofold axis which is situated in the plane of complex. Naturally, in this molecule the distribution of bonds' lengths and angles are symmetrical, relative to this axis. General view of the complex molecule is presented in figure 1. Bond lengths for $\mathbf{1}$ and analogous distances for complexes described in literature are listed in the table 2 .

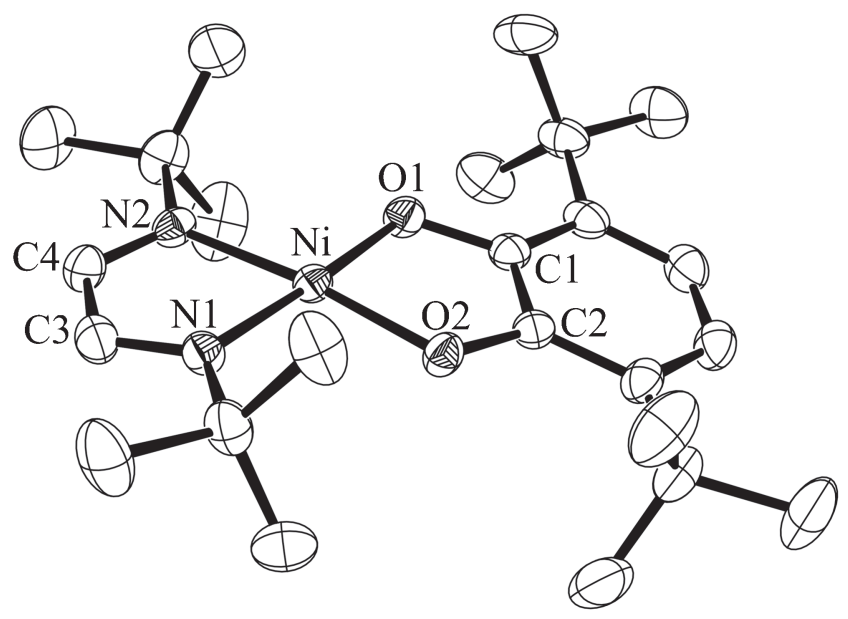

Figure 1. General view of complex 1 molecule. (30\% of ellipsoids probabilities, hydrogen atoms are omitted for clarity, atoms numeration is arbitrary and corresponds to numeration in table 1).

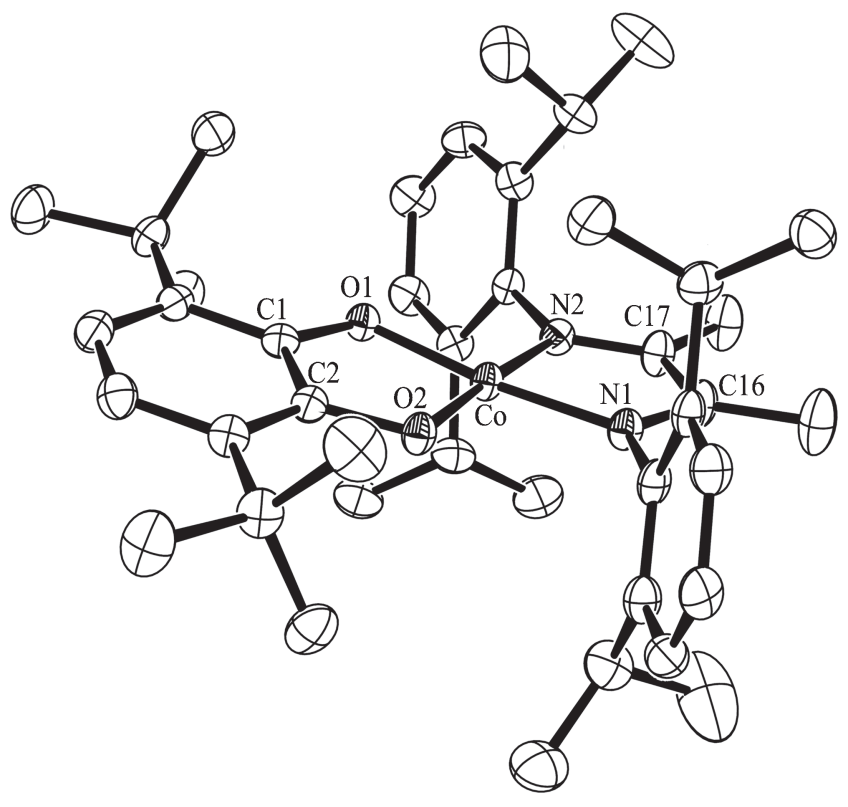

Figure 2. General view of complex 9 molecule. (50\% of ellipsoids probabilities, hydrogen atoms are omitted for clarity).

Bond lengths of $\mathrm{C}-\mathrm{O}$ and $\mathrm{C} 1-\mathrm{C} 2$ in chelate cycle of catecholato fragment characterize it valent state. It is known that these distances for anion-radical are in the range: C-O: $1.27-1.31 \AA$ and C1-C2: $1.32-1.39 \AA$; for catecholato dianion: $1.31-1.35 \AA$ and $1.36-1.42 \AA$ respectively. ${ }^{19}$ In the case of $\mathbf{1}$ bond lengths (C-O:

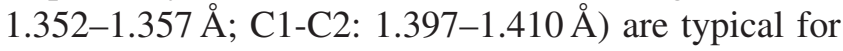
catecholato dianion coordination mode.

Bond length of $\mathrm{C}=\mathrm{N}$ of diazabutadiene in $\mathbf{1}$ (1.260-1.275 $\AA$ ) which are sensitive to ligand oxidation state are close to that, found for corresponding distances in coordinated neutral ligand in $(\text { tert-Bu })_{2}$ $(\mathrm{DAB})(\mathrm{H}, \mathrm{H}) \mathrm{NiBr}_{2}: 1.275 \AA^{20}{ }^{20}$

Bond lengths of $\mathrm{C} 3-\mathrm{C} 4$ and $\mathrm{Ni}-\mathrm{N}$ in catecholate complex 1 are slightly shorter than the same distances in corresponding dibromide: (tert-Bu $)_{2}(\mathrm{DAB})(\mathrm{H}, \mathrm{H})$ $\mathrm{NiBr}_{2}$ : C-C $1.470 \AA$, Ni-N 1.996, $2.002 \AA$; and in free diazabutadiene: C-C $1.496 \AA$. It can be the consequence of the difference in the structures of complexes. (DAB) $\mathrm{NiBr}_{2}$ has distorted tetrahedral geometry. Square-planar configuration of $\mathbf{1}$ promotes $\pi-\pi$-interaction through the molecule skeleton. In the case of $\mathrm{Ni}(3,6-\mathrm{DBSQ})_{2}$, which molecule is square-planar, $\pi-\pi$ interaction results in strong anti-ferromagnetic coupling of unpaired electrons localized in ligands $\pi$-systems. ${ }^{21}$

Complex 9 was also structurally characterized. General view of complex molecule is presented in the figure 2. Selected bonds lengths are listed in the table 3 . Unit cell of 9 contains the guest molecule of n-hexane.

Like 1, complex 9 has square-planar coordination core. The geometry of each ligand's fragment is very 
Table 2. Bond length intervals for complex $\mathbf{1}$ molecule (atoms numeration is arbitrary and corresponds to numeration in figure 1) and analogous distances for complexes described in literature.

\begin{tabular}{lccc}
\hline Bond & Complex 1 range $(\AA)$ & $\left(\mathrm{Me}_{2} \mathrm{Ph}\right) \mathrm{DAB}\left(\mathrm{Me}_{2}\right) \mathrm{Ni}\left(\mathrm{Cat}-\mathrm{Cl}_{4}\right)^{7}(\AA)$ & $\left(\mathrm{i}-\mathrm{Pr}_{2} \mathrm{Ph}\right) \mathrm{DAB}\left(\mathrm{Me}_{2}\right) \mathrm{Ni}\left(\mathrm{Cat}-\mathrm{Cl}_{4}\right)^{7}(\AA)$ \\
\hline $\mathrm{C}-\mathrm{O}$ & $1.352-1.357$ & $1.330 / 1.333$ & $1.332 / 1.329$ \\
$\mathrm{C}=\mathrm{N}$ & $1.260-1.275$ & $1.299 / 1.302$ & $1.299 / 1.297$ \\
$\mathrm{Ni}-\mathrm{O}$ & $1.823-1.829$ & $1.824 / 1.837$ & $1.830 / 1.828$ \\
$\mathrm{Ni}-\mathrm{N}$ & $1.938-1.959$ & $1.860 / 1.870$ & $1.860 / 1.869$ \\
$\mathrm{C} 1-\mathrm{C} 2$ & $1.397-1.410$ & 1.408 & 1.412 \\
$\mathrm{C} 3-\mathrm{C} 4$ & $1.436-1.448$ & 1.480 & 1.481 \\
\hline
\end{tabular}

close to planar. Planes of ligands are slightly twisted. The angle between planes is $6.83^{\circ}$. Bond lengths in chelate ring of catecholato fragment are typical for catecholato-dianion coordination mode. Squareplanar geometry is unusual for $\mathrm{Co}$ (II) compounds in such type of environment. Most of tetracoordinative cobalt(II) compounds with separated chelate ligands containing $\mathrm{N}$ - and $\mathrm{O}$-atoms have distorted tetrahedron geometry. The exceptions are: bis-iminosemiquinonato complexes, ${ }^{22,23}$ catecholato cobalt with amino-pyridine, ${ }^{11,12}$ and a number of complexes, where salicylaldiminato ligands are connected by a bridge. Table 4 presents a number of $\mathrm{Co}-\mathrm{N}$ and $\mathrm{C}=\mathrm{N}$ bond lengths for close analogs - bis(salicylaldiminato)cobalt complexes of different symmetry. (Bonds lengths are cited from reference. ${ }^{24}$ ) In distorted tetrahedron geometry Co-N and $\mathrm{C}=\mathrm{N}$ bonds' lengths are in the ranges: 1.951-2.034 and 1.279-1.299 $\AA$, whereas in distorted square-planar one they are: $1.849-1.883$ and $1.284-1.309 \AA$ respectively. It is evident that in tetrahedron, $\mathrm{Co}-\mathrm{N}$ bonds are longer and $\mathrm{C}=\mathrm{N}$ bonds are shorter than the same distances in square-planar coordination core. Square-planar geometry seems to be stabilized by $\pi$ - back donation from filled $\mathrm{d}_{\pi}$-orbitals of cobalt to empty anti-bonding $\pi$-orbitals of $\mathrm{N}$-donor. As a consequence, it results in shortening of $\mathrm{Co}-\mathrm{N}$ bond lengths and elongation of $\mathrm{C}=\mathrm{N}$ distances. Bond lengths in $\mathbf{9}$ confirm this rule.

So, according to the presented data, diazabutadiene complexes of nickel and cobalt are catecholato derivatives of divalent metal ions with neutral diazabutadiens. Additional $\pi-\pi$ bonding of diazabutadienes with metals is observed for both compounds $\mathbf{1}$ and $\mathbf{9}$.

\subsection{Some reactions of diazabutadiene-catecholato complexes of nickel and cobalt}

Neutral ligands in diazabutadiene-catecholato complexes of cobalt and nickel undergo substitution reactions. Resulting compounds were isolated and characterized. The same products were obtained independently by exchange reactions. The identity of the complexes synthesized by different ways was confirmed by identity of their IR spectra.

1,2-Bis(diphenylphosphino)ethane (dppe) can substitute any DAB ligand in nickel catecholates 1-4 but only 1,4-di-(tert-Bu)-diazabutadiene in cobalt complex 7 (schemes 5,6). Di-aryl-derived diazabutadiens in cobalt compounds are not being substituted. Resulting (dppe)MCat compounds were synthesized independently by exchange reaction with catecholato thallium.

Diazabutadiene ligands undergo substitution reaction also upon action of stronger base 2,2'-bpy on both cobalt and nickel catecholates (scheme 7).

Complexes 1-6 undergo one-electron chemical oxidation by silver cation forming stable paramagnetic adducts which were studied by EPR in solution (scheme 8, figure 3). EPR spectral parameters are listed in table 5 .

g-Factors and values of hyperfine coupling constants on protons of semiquinonato ligand indicate that unpaired electron is localized in $\pi$-system of semiquinonato fragment. ${ }^{34}$ It means that nickel oxidative state remains unchanged but catecholato ligand undergoes oxidation. Small values of hyperfine coupling constants on ${ }^{31} \mathrm{P}$ of dppe and the absence of hyperfine

Table 3. Selected bond lengths and angles of complex 9.

\begin{tabular}{lccccc}
\hline Bond & Distance $(\AA)$ & Bond & Distance $(\AA)$ & Atoms & Angles $\left(^{\circ}\right)$ \\
\hline Co-N1 & $1.8743(16)$ & Co-O1 & $1.8066(13)$ & O1-Co-N1 & 173.66 \\
Co-N2 & $1.8711(16)$ & Co-O2 & $1.8104(13)$ & O2-Co-N2 & 176.91 \\
N1-C16 & $1.323(2)$ & O1-C1 & $1.364(2)$ & C1-O1-Co-N2 & 178.92 \\
N2-C17 & $1.323(2)$ & O2-C2 & $1.359(2)$ & C2-O2-Co-N1 & 175.14 \\
C16-C17 & $1.439(3)$ & C1-C2 & $1.406(3)$ & O1-Co-N2-C17 & 172.72 \\
& & & & O2-Co-N1-C16 & 177.64 \\
\hline
\end{tabular}


Table 4. Selected bond lengths ( $\AA$ ) for several bis(salicylaldiminato)cobalt and 9 .

\begin{tabular}{|c|c|c|c|c|c|}
\hline & \multirow[t]{2}{*}{ Complex geometry, title and reference } & \multicolumn{2}{|c|}{ Ligand 1} & \multicolumn{2}{|c|}{ Ligand 2} \\
\hline & & Co-N & $\mathrm{C}=\mathrm{N}$ & Co-N & $\mathrm{C}=\mathrm{N}$ \\
\hline \multirow[t]{3}{*}{ Distorted tetrahedron } & bis(salicylal-N-m-anisidinato)-cobalt(II) ${ }^{25}$ & 1.951 & 1.279 & 1.965 & 1.299 \\
\hline & $\begin{array}{l}\text { bis(N-(2,6-dimethylphenyl)- } \\
\text { salicylaldiminato-N,O)-cobalt(II })^{26}\end{array}$ & 2.002 & 1.288 & 2.034 & 1.279 \\
\hline & $\begin{array}{l}\text { bis(3-tert-butyl-N,5-dimethylsalicyl- } \\
\text { aldiminato)-cobalt(II) }{ }^{27}\end{array}$ & 1.975 & 1.286 & 1.966 & 1.288 \\
\hline \multirow[t]{7}{*}{ Distorted square-planar } & $\begin{array}{l}(\mathrm{R}, \mathrm{R})-\left(\mathrm{N}, \mathrm{N}^{\prime} \text {-bis }\left(2^{\prime} \text {-hydroxybenzyli- }\right.\right. \\
\text { dene)-1,2-diaminocyclohexane- } \\
\left.\mathrm{N}, \mathrm{N}^{\prime}, \mathrm{O}, \mathrm{O}^{\prime}\right) \text {-cobalt }(\mathrm{II})^{28}\end{array}$ & 1.871 & 1.293 & 1.872 & 1.296 \\
\hline & $\begin{array}{l}\text { (N,N'-(o-phenylene)- } \\
\text { bis(salicylideneaminato ))-cobalt(II })^{29}\end{array}$ & 1.873 & 1.308 & 1.870 & 1.300 \\
\hline & $\begin{array}{l}\mathrm{N}, \mathrm{N}^{\prime} \text {-ethylene-bis(3-tert- } \\
\text { butylsalicylideneiminato)-cobalt(II) }\end{array}$ & 1.849 & 1.289 & 1.849 & 1.289 \\
\hline & $\begin{array}{l}\text { (N,N'-bis(3-tert-butyl-5- } \\
\text { methylsalicylidene)-2,3-diamino-2,3- } \\
\text { dimethylbutane)-cobalt(II) }\end{array}$ & 1.860 & 1.293 & 1.860 & 1.293 \\
\hline & $\begin{array}{l}\text { meso-(N,N'-cyclohexylene- } \\
\text { bis(salicylideneiminato)-cobalt(II) })^{32}\end{array}$ & 1.881 & 1.305 & 1.883 & 1.284 \\
\hline & $\begin{array}{l}\mathrm{N}, \mathrm{N}^{\prime} \text {-bis }(3,5 \text {-di-tert--butylsalicylidene- } \\
1,2 \text {-phenylenediamine)-cobalt(II) })^{33}\end{array}$ & 1.860 & 1.309 & 1.860 & 1.305 \\
\hline & Complex 9 (this work) & $1.873 / 1.859$ & $1.312 / 1.331$ & & \\
\hline
\end{tabular}

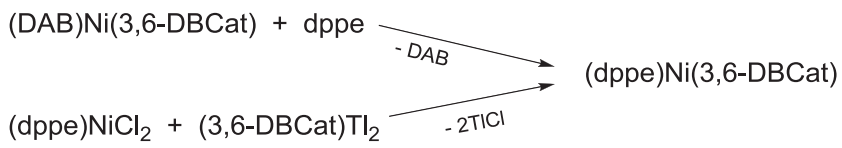

Scheme 5. Substitution of DAB by dppe in catecholato nickel compounds and independent synthetic way to (dppe) Ni(3,6-DBCat).

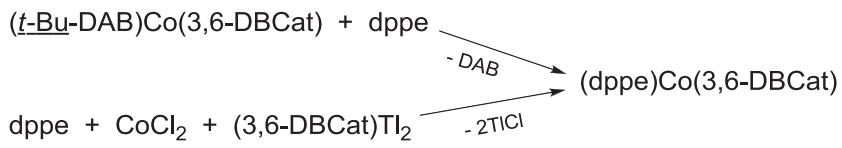

Scheme 6. Substitution of $t$-Bu-DAB by dppe in catecholato cobalt compound and independent synthetic way to (dppe) $\operatorname{Co}(3,6-\mathrm{DBCat})$.

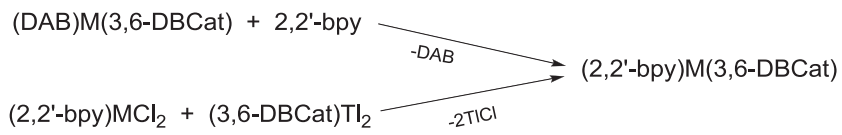
$\mathrm{M}=\mathrm{Co}, \mathrm{Ni}$

Scheme 7. Substitution of DAB by $2,2^{\prime}$ bpy in nickel and cobalt catecholates and independent way to $\left(2,2^{\prime}\right.$ bpy $) \mathrm{M}(3,6-$ DBCat), $\mathrm{M}=\mathrm{Ni}$, Co.

$(\mathrm{L}) \mathrm{Ni}(3,6-\mathrm{DBCat})+\mathrm{AgBF}_{4}$

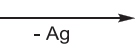

$[(\mathrm{L}) \mathrm{Ni}(3,6-\mathrm{DBSQ})]^{+}\left(\mathrm{BF}_{4}\right)^{-}$

Scheme 8. Oxidation of catecholato nickel complexes into corresponding semi quinonato cations. coupling with ${ }^{14} \mathrm{~N}$ of $\mathrm{DAB}$ indicate that squareplanar structure remains unchanged upon oxidation. ${ }^{34,35}$ EPR spectral parameters of cations do not depend on temperature and nature of diazabutadiene. It means that no redox-isomeric transformations occur. It should be mentioned that EPR spectral parameters of [(dppe) $\mathrm{Ni}(3,6-\mathrm{DBSQ})]^{+}$cation coincide with those obtained by electrochemical oxidation of the same complex ${ }^{36}$ and are similar to that obtained for analogous catecholates. ${ }^{10}$

Anisotropic EPR spectrum with axial symmetry of g-tensor was recorded for powder of 9 at $\mathrm{T}=140 \mathrm{~K}$. Hyperfine coupling with ${ }^{59} \mathrm{Co}$ nucleus was not detected. g-Tensor parameters: $\mathrm{g}_{\perp} \cong 1.90, \mathrm{~g}_{\|} \cong 3.36$ indicate $\mathrm{Co}(\mathrm{II}), \mathrm{d}^{7}$ ground state to be low spin. No EPR

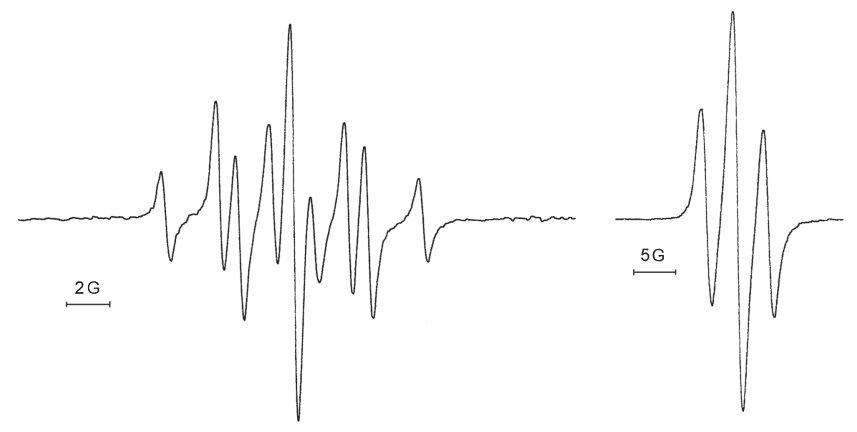

Figure 3. EPR spectra of cations $[\mathbf{6}]^{+}$(left) and $[\mathbf{1}]^{+}$ (right) $\left(\mathrm{CH}_{2} \mathrm{Cl}_{2}, 290 \mathrm{~K}\right)$. 
Table 5. EPR spectral parameters of nickel semiquinonato cations.

\begin{tabular}{lccc}
\hline Complex & g-factor & $\mathrm{a}_{i}\left({ }^{1} \mathrm{H}\right)_{\mathrm{SQ}}, \mathrm{G}$ & $\mathrm{a}_{i}\left({ }^{31} \mathrm{P}\right), \mathrm{G}$ \\
\hline $\mathbf{1}^{+}$ & 2.0136 & 3.55 & - \\
$\mathbf{2}^{+}$ & 2.0041 & 3.60 & - \\
$\mathbf{3}^{+}$ & 2.0048 & 3.40 & - \\
$\mathbf{4}^{+}$ & 2.0034 & 3.65 & - \\
$\mathbf{5}^{+}$ & 2.0058 & 3.40 & - \\
$\mathbf{6}^{+}$ & 2.0041 & 3.68 & 2.52 \\
\hline
\end{tabular}

$(t-\mathrm{Bu}-\mathrm{DAB}) \mathrm{Ni}(3,6-\mathrm{DBCat})+3,6-\mathrm{DBQ}$

$\left.\mathrm{Ni}(3,6-\mathrm{DBSQ})_{2}+(t-\mathrm{Bu}-) \mathrm{DAB}\right)$

$(t-B u-D A B) N i(3,6-D B S Q)_{2}$

Scheme 9. Oxidative addition of $o$-quinone to nickel catecholate leads to bis-o-semiquinonato nickel compound.

spectra for cobalt(II) catecholate complexes in solution were observed in the temperature range of $77-300 \mathrm{~K}$.

THF solution of (dppe)Co(3,6-DBCat) when exposed to air quickly changes its colour from brown to blue, which is typical for semiquinonate anion radical formation. n-Hexane addition causes colourless solid precipitation. IR spectrum of precipitate contains a very intensive band at $v=1185 \mathrm{sm}^{-1}$, which can be attributed to $\nu_{\mathrm{P}}=\mathrm{O}$.

Oxidative addition of 3,6-DBQ to $\mathbf{1}$ leads to extending of nickel coordination sphere with simultaneous oxidation of catecholato ligand. Complex of the same composition can be obtained independently from bis(semiquinonato)nickel and diazabutadiene (scheme 9). Interaction of the complexes 2-4, which have more sterically hindered DAB-ligand, with $3,6-\mathrm{DBQ}$ is more complicated and will be the subject of a future publication.

Oxidative addition reaction of (dppe)Co(3,6-DBCat) with different $o$-quinones was used for synthesis of six-coordinated cobalt adducts containing $o$-quinonato fragments of different nature and consequently having different oxidative state. ${ }^{16}$

\section{Conclusions}

A number of new catecholato complexes of nickel and cobalt with diazabutadienes and 2,2'-bpy were synthesized. Structural study of two complexes indicated square-planar molecules containing divalent metals, catecholato-dianions and neutral diazabutadienes. Nickel complexes undergo chemical oxidation through catecholate ligand, forming semiquinonato nickel compounds. Square planar geometry remains unchanged upon oxidation.

\section{Supplementary Information}

CCDC-678237 (1) and CCDC- 678238 (9) contain the supplementary crystallographic data, which can be obtained free of charge at www.ccdc.cam.ac.uk/ conts/retrieving.html or from the Cambridge Crystallographic Data Centre, 12 Union Road, Cambridge CB2 1EZ, UK; Fax: (internat.) + 44-1223-336-033; E-mail: deposit@ccdc.cam.ac.uk. Check CIF files are avaialble at www.ias.ac.in/chemsci

\section{Acknowledgements}

The authors are thankful to L. Abakumova, N. Khamaletdinova and O. Kuznetcova for IR spectra recording. This work was supported by RFBR (grants: 13-03-97070), by Russian President Grant supporting scientific schools (NSh-271.2014.3), by Program of presidium of RAS $\mathcal{N}$ o 18 . This research was partly supported by the grant (the agreement of August 27, 2013 No 02.B.49.21.0003 between The Ministry of education and science of the Russian Federation and Lobachevsky State University of Nizhni Novgorod).

\section{References}

1. Balch A L 1973 J. Amer. Chem. Soc. 952723

2. Razuvaev G A, Teplova I A, Shalnova K G and Abakumov G A 1978 J. Organometal. Chem. 157353

3. Buchanan R M and Pierpont C G 1980 J. Amer. Chem. Soc. 1024951

4. Abakumov G A, Garnov V A, Nevodchikov V I and Cherkasov V K 1989 Dokl. RAN 304107

5. Abakumov G A, Razuvaev G A, Nevodchikov V I and Cherkasov V K 1988 J. Organomet. Chem. 341485

6. Speier G, Tyeklar Z, Toth P, Speier E, Tisza S, Rockenbauer A, Whalen A M, Alkire N and Pierpont C G 2001 Inorg. Chem. 405653

7. Brasse M, Campora J, Davies M, Teuma E, Palma P, Alvarez E, Sanz E and Reyes M L 2007 Adv. Synth. Catal. 3492111

8. Shimazaki Y, Tani F, Fukui K, Naruta Y and Yamauchi O 2003 J. Amer. Chem. Soc. 12510512

9. Bowmaker G A, Boyd P D W and Campbell G K 1982 Inorg. Chem. 212403

10. Klein H-F, Auer E, Dal A, Lemke U, Lemke M, Jung T, Rohr C, Florke U and Haupt H-J 1999 Inorg. Chim. Acta 287167

11. Ohtsu H and Tanaka K 2004 Angew. Chem., Int. Ed. 43 6301

12. Ohtsu H and Tanaka K 2005 Chem. Eur. J. 113420

13. Belostotskaya I S, Kommisarova N L, Dzhuaran E V and Ershov V V 1972 Izv. AN SSSR, Ser. Khim. 1594

14. Van Koten G and Vrieze K 1982 In Advances in Organometallic Chemistry F G A Stone and R West (Eds.) (NY: Academic Press) Vol. 21 p.152 (and references therein) 
15. Venanzi L M 1958 J. Chem. Soc. 719

16. Bubnov M P, Teplova I A, Cherkasov V K and Abakumov G A 2003 European J. Inorg. Chem. 2519

17. Sheldrick G M 2000 SHELXTL v. 6.12, Structure Determination Software Suite, Bruker AXS, Madison, Wisconsin, USA

18. Sheldrick G M 1998 SADABS v.2.01, Bruker/Siemens Area Detector Absorption Correction Program, Bruker AXS, Madison, Wisconsin, USA

19. Pierpont C G and Lange C 1981 Coord. Chem. Rev. 38 45

20. Jameson G B, Oswald H R and Beer H R 1984 J. Amer. Chem. Soc. 1061669

21. Abakumov G A, Cherkasov V K, Bubnov M P, Ellert O G, Rakitin Yu V, Zakharov L N, Struchkov Yu T and Saf'yanov Yu N 1992 Izv. Akad. Nauk, Ser. Khim. 2315

22. Bill E, Bothe E, Chaudhuri P, Chlopek K, Herebian D, Kokatam S, Ray K, Weyhermuller T, Neese F and Wieghardt K 2005 Chem. Eur. J. 11204

23. Poddel'sky A I, Cherkasov V K, Fukin G K, Bubnov M P, Abakumova L G and Abakumov G A 2004 Inorg. Chim. Acta 3573632

24. Allen F H 2002 Acta Cryst. B 58380

25. Knyazeva A N and Shkol'nikova L M 1973 J. Struct. Chem. 141058
26. McKenzie E D, Selvey S J and Nowell I W 1985 Inorg. Chim. Acta 10185

27. Li X, Huang L, Dong S, Li M and Sun H 2005 Acta Crystallogr. Sect. E: Struct. Rep. Online 61465

28. Belokon Y N, Fuentes J, North M and Steed J W 2004 Tetrahedron 603191

29. Pahor N B, Calligaris M, Delise P, Dodic G, Nardin G and Randaccio L 1976 J. Chem. Soc., Dalton Trans. 2478

30. Schaefer W P, Huie B T, Kurilla M G and Ealick S E 1980 Inorg. Chem. 19340

31. Bottcher A, Elias H, Jager E-G, Langfelderova H, Mazur M, Muller L, Paulus H, Pelikan P, Rudolph M and Valko M 1993 Inorg. Chem. 324131

32. Bresciani N, Calligaris M, Nardin G and Randaccio L 1974 J. Chem. Soc., Dalton Trans. 1606

33. Peretti K L, Ajiro H, Cohen C T, Lobkovsky E B and Coates G W 2005 J. Am. Chem. Soc. 12711566

34. Razuvaev G A, Cherkasov V K and Abakumov G A 1978 J. Organomet. Chem. 160361

35. Nevodchikov V I, Abakumov G A, Cherkasov V K and Razuvaev G A 1981 J. Organomet. Chem. 214119

36. Kadirov M K, Budnikova Yu H, Gryaznova T V, Sinyashin O G, Bubnov M P, Krashilina A V and Cherkasov V K 2007 Izv. Akad. Nauk. Ser. Khim. 99 